NASA/TM-2004-212914

NASA's Microgravity Fluid Physics Strategic Research Roadmap

Brian J. Motil and Bhim S. Singh

Glenn Research Center, Cleveland, Ohio 
Since its founding, NASA has been dedicated to the advancement of aeronautics and space science. The NASA Scientific and Technical Information (STI) Program Office plays a key part in helping NASA maintain this important role.

The NASA STI Program Office is operated by Langley Research Center, the Lead Center for NASA's scientific and technical information. The NASA STI Program Office provides access to the NASA STI Database, the largest collection of aeronautical and space science STI in the world. The Program Office is also NASA's institutional mechanism for disseminating the results of its research and development activities. These results are published by NASA in the NASA STI Report Series, which includes the following report types:

- TECHNICAL PUBLICATION. Reports of completed research or a major significant phase of research that present the results of NASA programs and include extensive data or theoretical analysis. Includes compilations of significant scientific and technical data and information deemed to be of continuing reference value. NASA's counterpart of peerreviewed formal professional papers but has less stringent limitations on manuscript length and extent of graphic presentations.

- TECHNICAL MEMORANDUM. Scientific and technical findings that are preliminary or of specialized interest, e.g., quick release reports, working papers, and bibliographies that contain minimal annotation. Does not contain extensive analysis.

- CONTRACTOR REPORT. Scientific and technical findings by NASA-sponsored contractors and grantees.
- CONFERENCE PUBLICATION. Collected papers from scientific and technical conferences, symposia, seminars, or other meetings sponsored or cosponsored by NASA.

- SPECIAL PUBLICATION. Scientific, technical, or historical information from NASA programs, projects, and missions, often concerned with subjects having substantial public interest.

- TECHNICAL TRANSLATION. Englishlanguage translations of foreign scientific and technical material pertinent to NASA's mission.

Specialized services that complement the STI Program Office's diverse offerings include creating custom thesauri, building customized databases, organizing and publishing research results ... even providing videos.

For more information about the NASA STI Program Office, see the following:

- Access the NASA STI Program Home Page at http://www.sti.nasa.gov

- E-mail your question via the Internet to help@sti.nasa.gov

- Fax your question to the NASA Access Help Desk at 301-621-0134

- Telephone the NASA Access Help Desk at 301-621-0390

- Write to:

NASA Access Help Desk

NASA Center for AeroSpace Information 7121 Standard Drive

Hanover, MD 21076 
NASA/TM-2004-212914

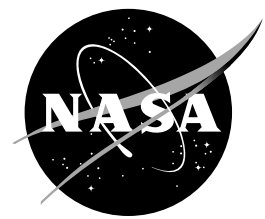

NASA's Microgravity Fluid Physics Strategic Research Roadmap

Brian J. Motil and Bhim S. Singh

Glenn Research Center, Cleveland, Ohio

Prepared for the

42nd Aerospace Sciences Meeting and Exhibit

sponsored by the American Institute of Aeronautics and Astronautics

Reno, Nevada, January 5-8, 2004

National Aeronautics and

Space Administration

Glenn Research Center 


\section{Acknowledgments}

This work was supported by the Physical Sciences Research Division of NASA's Office of Biological and Physical Research. The authors gratefully acknowledge the assistance of members of the Microgravity Fluid Physics Branch at NASA Glenn Research Center and the National Center for Microgravity Research for their support of Strategic Workshops and final reports used to develop this paper. We particularly acknowledge the help of

Francis Chiaramonte, Eric Golliher, Fred Kohl, John McQuillen, Henry Nahra, and John Sankovic.

Available from

NASA Center for Aerospace Information 7121 Standard Drive

Hanover, MD 21076
National Technical Information Service 5285 Port Royal Road Springfield, VA 22100 


\title{
NASA'S MICROGRAVITY FLUID PHYSICS STRATEGIC RESEARCH ROADMAP
}

\author{
Brian J. Motil ${ }^{*}$ and Bhim S. Singh \\ National Aeronautics and Space Administration \\ Glenn Research Center \\ Cleveland, Ohio 44135
}

\begin{abstract}
The Microgravity Fluid Physics Program at NASA has developed a substantial investigator base engaging a broad cross-section of the U.S. scientific community. As a result, it enjoys a rich history of many significant scientific achievements. The research supported by the program has produced many important findings that have been published in prestigious journals such as Science, Nature, Journal of Fluid Mechanics, Physics of Fluids, and many others. The focus of the program so far has primarily been on fundamental scientific studies. However, a recent shift in emphasis at NASA to develop advanced technologies to enable future exploration of space has provided motivation to add a strategic research component to the program. This has set into motion a year of intense planning within NASA including three workshops to solicit inputs from the external scientific community. The planning activities and the workshops have resulted in a prioritized list of strategic research issues along with a corresponding detailed roadmap specific to fluid physics. The results of these activities were provided to NASA's Office of Biological and Physical Research (OBPR) to support the development of the Enterprise Strategy document. ${ }^{1}$ This paper summarizes these results while showing how the planned research supports NASA's overall vision through OBPR's organizing questions.
\end{abstract}

\section{INTRODUCTION}

A defining characteristic of humans is the desire to continually explore beyond our established boundaries. It is this characteristic that continually drives us all to dream of long duration human-tended missions well beyond Low Earth Orbit (LEO). Unfortunately, our current technology prevents us from realizing that dream. Our future explorers must be equipped with a spectrum of technologies to support and protect life during space travel as well as provide the ability to utilize available resources once at the final destination. NASA is formulating an ambitious plan for developing advanced technologies that can enable future exploration missions with capabilities not possible from today's technology. The Office of Biological and Physical Research (OBPR) brings the unique element of the effects of the space environment (low-gravity, radiation, etc.) on crew members as well as spacecraft systems in enabling NASA's vision. The Microgravity Fluid Physics Program falls in the Physical Sciences Research Division (PSRD) of OBPR. Since fluids are ubiquitous in the human body as well as in many spacecraft systems, an understanding of fluid behavior in a reduced-gravity environment is critical to the success of many technologies and countermeasures required to extend life beyond LEO.

To date, primary emphasis of the Microgravity Fluid Physics Program has been on fundamental research. However, much of the fundamental research in areas such as dynamics and instability; multiphase flow and phase change; interfacial phenomena; and complex fluids has provided a crucial knowledge base applicable to the development of advanced exploration technologies. ${ }^{2}$ The Microgravity Fluid Physics Program has developed a strategic research roadmap to identify the most critical research required to enable these technologies. This roadmap, developed with strong participation from the external scientific community, fed into the development of the OBPR strategy document. As a result, the discipline roadmap aligns well with the OBPR strategy document and 10-year research plan. Much of this work is a result of workshops held this summer and will be discussed in detail. In the coming year, the Microgravity Fluid Physics Program will begin the implementation of its strategic research plan. NASA's fiscal 2004 budget contains significant funding for this purpose under the Human Research Initiative.

\section{STRATEGIC RESEARCH: LINK TO NASA'S} VISION THROUGH ORGANIZING QUESTIONS NASA's desire to enable humans to explore the next frontier, i.e., to travel beyond LEO, is embodied in the second pillar of its guiding vision: "to extend life to there." The Agency fully realizes that to successfully embark on missions of this type, our current technological capabilities must improve and very specific questions must be addressed. Guided by NASA's vision, OBPR has developed a 10-year research plan based on five organizing questions: ${ }^{1}$

\footnotetext{
${ }^{*}$ Member, AIAA.
} 
1. How can we assure the survival of humans traveling far from Earth?

2. How does life respond to gravity and space environments?

3. What new opportunities can research bring to expand understanding of the laws of nature and enrich lives on Earth?

4. What technology must we create to enable the next explorers to go beyond where we have been?

5. How can we educate and inspire the next generation to take the journey?

These are clearly not easy questions to answer and each question requires involvement from many different disciplines. OBPR developed a more detailed subset of questions to guide the disciplines and address each of the organizing questions in terms of specific targets and technologies enabled. The Microgravity Fluid Physics strategic research plan presented here is developed to specifically address the first two detailed questions under organizing question four.

4a. How can we enable the next generation of autonomous, reliable spacecraft human support subsystems?

4b. What new reduced-gravity engineering systems and advanced materials are required to enable efficient and safe deep-space travel?

\section{LAYING THE GROUNDWORK}

The process of developing a comprehensive roadmap for the Microgravity Fluid Physics Program evolved around the input from three workshops. The first two were organized to specifically address strategic research themes. The first workshop (May 5-7, 2003) was organized to address research issues associated with the control of fine particulates in closed-loop systems; the second (May 15, 2003) was to address the multiphase fluid problems associated with power, propulsion and advanced life support. A third workshop was held later in the year (August 11-13, 2003) to initiate a dialogue between the Advanced Human Support Technology (AHST) and the Microgravity Physical Science research communities and lead to the identification and prioritization of fluids, transport and reaction problems associated with AHST. The intent was also to lay the groundwork for strategic collaborative investigations between the two groups. In addition to the workshops, planning for an International Space Station (ISS) multiphase flow facility was initiated and is expected to be funded beginning in 2004. This section summarizes the results of each of the workshops. Full reports are electronically available. ${ }^{3,4}$
Fine Particulate Workshop

The objectives of this workshop were to identify problems associated with the control of fine particulates in a variety of closed-loop systems in the ISS and to recognize that the flow behavior of fine particulates is fundamentally altered with the absence of gravitational settling/screening. Human living environments produce fine particulates in the form of skin flakes, clothing fibers, and other substances from food and hygiene operations, or operating machinery. The living environment may also contain particulates carried into the area on the surfaces of clothing, skin, equipment or supplies. Microgravity changes the relative importance of many factors affecting fine particulate behavior. In microgravity settling does not occur; thus, the residence time for different-sized airborne particulates is significantly altered from terrestrial conditions. The lack of a settling force has several consequences, none of which has been quantitatively investigated. It is hypothesized that aggregation, due either to Brownian diffusion of small particles towards large particles or shear-induced collisions of large particles are enhanced in microgravity. It is also expected that entrainment of particles and the effects of surface to particle adhesion forces may be altered. The resulting size distribution of airborne aggregates is expected to be substantially different from the size distributions of dust aggregates found in terrestrially-based living environments.

Initial research targets identified by the workshop were to develop models and increase an understanding of:

- Particle aggregation and size distribution in the absence of gravity driven settling.

- The effects of larger aggregates on deposition rates and how this can impact filtration devices.

- The mechanisms for the generation of fine particulates in closed loop systems including devices to effectively separate fine particulate from liquids and gases.

Strategic Research Workshop on Two-Phase Flow, Fluid Stability and Dynamics

This workshop was specifically designed to assess and prioritize multiphase flow issues associated with space power; propulsion; fluid and thermal management; and advanced life support systems. It was somewhat different than the other two, because the subject research issues had been adequately identified in previous workshops ${ }^{5-7}$ and studies. ${ }^{8}$ As a result, rather than revisiting these findings, common themes and technological issues were assembled and distributed before the workshop to the participants. The invited 
experts included researchers and engineers from academia, industry and government. They were instructed to come prepared to discuss and debate the priority of each problem and to participate in formulating a detailed plan or roadmap to address the most critical areas. Finally, they were asked to review and comment on a near-term experimental plan to utilize the ISS facilities for a two-phase flow experiment.

The scheme used to prioritize the technical issues involved four categories defined as

a. Critical-Must be resolved to achieve NASA's mission.

b. Severely Limiting-Resolution provides significant savings to mission (cost, weight, etc.).

c. Enhancement-Resolution increases reliability or provides moderate savings to mission.

d. Awareness-Better understanding may lead to resolution of higher priority problems.

In general, phase change and multiphase flow are considered mission-enabling for power, propulsion, and closed-loop advanced life support systems capable of long duration flights. Not only are there many processes where these technologies are unavoidable such as in a water recycling system or partially filled fuel tank, but they also offer higher efficiencies and weight savings that are essential when re-supply missions are not feasible. System designers must be able to accurately predict the basic behavior of these systems through a combination of two-fluid models, empirical correlations, and experimental reduced gravity data.

The following specific aspects of phase change and multiphase flow were considered "critical" by the workshop:

- The ability to develop efficient phase separation methods as well as techniques to distribute and control each phase. This includes accurate models to predict the location of each phase.

- Development of systems that are either insensitive or can recover from potentially dangerous instabilities caused by flow changes; upset events; startup and shutdown; and changes in acceleration levels (zero up to several times normal gravity).

- Design of gravitationally-insensitive phase change components such as evaporators/condensers that can be functionally tested in normal gravity with the expectation of similar performance in space. Techniques to recover from "dry out" conditions in reduced gravity were also considered critical.
- Techniques to predict the proper contact angle at the free surface/solid junction (when the contact line location is not fixed) and to assess this uncertainty on fluid stability.

- Predictive capabilities, both computational and analytical, need to be developed to extend relatively small scale experimental results to practical full-scale systems.

The following specific aspects of phase change and multiphase flow were considered "severely limiting” by the workshop:

- Methods to enhance critical heat flux (CHF) under both pool and steady flow boiling conditions can significantly reduced the mass of heat exchangers and should be developed. Many large scale power and thermal management systems will use flow through evaporators and even small increases in the $\mathrm{CHF}$ can result in large savings. In addition, experiments focusing on condensation, primarily the drainage of liquid condensate films at low shear conditions, should be conducted including the measurement of the heat transfer coefficients.

- Understanding of flow through splitting/combining components (e.g., tees), through porous media, and into and out of accumulators is critical for many multiphase flow systems.

- Development of efficient techniques to fill and empty storage tanks, containers and accumulators involving a gas and liquid phases in space. Mass gauging techniques are also required to determine the mass of fluid present in a container or tank in space.

- A better understanding of the stability dynamics of disconnected capillary surfaces is needed in many capillary-driven two-phase devices such as heat pipes, capillary pumped loops, wicks, and axial grooves or vanes.

- Techniques to remove or position bubbles in a liquid are required for several specific systems such as a tissue growth bioreactor.

- In order to utilize the large-mass spacecraft needed for long duration missions, a full-scale experiment is required to examine the issues of fluid sloshing. While contact line dynamics have been successfully applied to smaller scale tanks and experiments, there has been no experimental verification of the behavior on a large scale.

The items considered critical and severely limiting were then used to develop the multiphase flow portion of the strategic research roadmap. The roadmap is discussed later in the paper along with the near-term experimental plan for a two-phase flow experiment. 
Workshop on Critical Issues in Microgravity Fluids, Transport, and Reaction Processes in Advanced Human Support Technology

The final workshop held later in the year was jointly organized with the Bioastronautics Research Division (Code UB) of OBPR with the purpose to bring together experts from both the Advanced Human Support Technology (AHST) and the Microgravity Physical Sciences communities in order to identify the most critical areas of strategic research related to advanced human support technologies and microgravity fluids, transport and reaction processes. As intended, the workshop also provided a forum to establish the groundwork for future strategic collaborative investigations.

The workshop focused on four key AHST areas: Air Revitalization, Solid Waste Management, Water Recovery Systems, and Thermal Systems and Phase Change Processes. Each area developed a summary of technical priorities which are discussed in this section. In addition to the specific areas, several organizational recommendations emerged. These included the need for increased collaboration between the AHST and microgravity research communities which should then lead to microgravity researchers participation in the development of AHST technologies beginning with the concept development phase through final hardware testing and on-orbit performance verification. Finally, the members proposed that NASA take the lead in compiling information into system-specific design guides detailing the fundamental mechanisms and predictive tools (models, equations, correlations) relevant to AHST systems. Of course, this recommendation should extend to power and propulsion systems as well. The final report for this workshop will be published as a NASA Technical Memorandum.

Air Revitalization: This splinter group evaluated the major Environmental Control and Life Support (ECLS) system functions and identified two major classifications - those that provide for basic crew survival and those that provide for and maintain crew health and safety. Oxygen supply and $\mathrm{CO}_{2}$ removal are classified within the functions that are critical for crew survival. Functions that provide for and maintain crew health and safety include fire detection and suppression, atmospheric humidity control, suspended particulate matter removal and disposal, trace chemical contaminant removal, and suspended microbe removal. The following specific recommendations were made:

- Leverage off near-term particulate matter measurement experiments to be conducted on board the ISS to better understand the particulate matter size distribution (below 10 microns) in a crewed spacecraft cabin.

- Coordinate an effort to understand fire signatures to make more reliable, robust fire detection systems for crewed spacecraft.

- Continue development of packed beds for carbon dioxide removal. Issues include fouling, monitoring, solid phase deposition from the reaction and morphology of catalyst fines, and microgravity effects on detection, ventilation and sensor effectiveness.

- Study phase separation and liquid degassing throughout the ECLS system. Research in these areas is cross-cutting through several ECLS system design sub-disciplines, e.g., oxygen production by water electrolysis, humidity control and airborne particulates (gas-solid separation).

Solid Waste Management: Current Solid Waste Management (SWM) systems perform only limited waste processing functions and are somewhat insensitive to microgravity conditions. Future SWM systems will likely become substantially more complex and microgravity sensitive, and include the processing functions of volume reduction, stabilization, sanitization, and resource recovery. Both fundamental and applied research is required to address the numerous anticipated SWM microgravity concerns. A fundamental understanding of the following issues is needed to facilitate applied SWM research and technology development:

- Handling and transport of solid waste for processing.

- Understanding of two and three-phase flow, with moisture contents ranging from very low (dried) to very high (slurry) levels.

- Microgravity-compliant monitoring and control systems.

Water Recovery: Since many water recovery systems require an understanding of microgravity fluid physics, the past approach has been to avoid two and threephase flow. The fluid flow problems in many of the water recovery systems are related to multiphase flow, scale-up, and biofouling. Well-conceived fundamental and applied research on these topics would provide useful information that could lead to new and better water recovery systems. Specific recommendations made include:

- Conduct studies on the influence of microgravity on multiphase flow systems. Being able to implement multiphase flow systems under microgravity conditions could permit the use of technologies for water recovery that have not been 
considered before. This could result in valuable advances in the technology for water recovery. This includes issues related to bubble coalescence and break-up, channeling in solid-liquid flows, mixing, bubble injection, preferential phase distribution, flow stability, flow regimes for microgravity multiphase flow, microgravity heat and mass transfer, contact angles and wetting, gasliquid separation, solid-liquid separation, dewatering, phase management, fluidization, capillarity, and liquid droplets.

- Develop scaling techniques. Water recovery systems are relatively large in size and must be operated over long-term durations. As a result, testing is fairly difficult. It is necessary to scale up the results from small-scale, short-term experiments in microgravity to large-scale, longlife functional systems. It is also necessary to scale-up experiments performed in Earth's gravity (which are relatively easy for large-scale, longterm testing) to account for microgravity.

- Understand the influence of microgravity on biofouling. Many water processing reactors require a chemical or biological film on the surface of a tube or bead. Important issues for biofilm reactors include biofilm sloughing and mass transport under microgravity conditions.

Thermal Systems: Thermal subsystems are critical in several areas of advanced human support technologies for long duration microgravity and planetary missions. This includes cabin temperature and humidity control, space suit thermal and humidity regulation, two-phase and single-phase energyconversion/power-cycles, refrigeration systems, thermal storage systems, and normal and cryogenic fluid storage tanks. Specific recommendations by this group include:

- Attain a phenomenological understanding and accumulation of empirical data for two-phase flow in complicated micro- and macro- geometries; boiling and condensation heat transfer; and phasedistribution and phase-transition phenomena, in microgravity.

- Develop empirical correlations, theoretical models, scaling laws, and comprehensive CFD codes for two-phase flow in complicated geometries; boiling and condensation heat transfer; and phase distribution and phase transition phenomena in microgravity.

- Develop stability criteria for two-phase heat transfer loops in microgravity.

- Develop advanced, efficient, reliable, low cost, and compact gas-liquid, solid-liquid, and solid-gas phase separation technologies for operation in variable gravity.
- Develop advanced, efficient, and reliable vapor compression heat pump technology.

- Investigate gravitational effects and transport mechanisms for two-phase flow in porous media.

- Develop reliable and low cost dynamic pressure control mechanisms for liquid storage tanks to eliminate venting.

\section{NEAR TERM ISS EXPERIMENTS}

Some level of research related to the strategic interests of NASA has always been a part of OBPR and the Fluid Physics Program. As a result, many ground based and several space flight experiments have yielded valuable information related to multiphase flow, phase change, and interfacial phenomena. ${ }^{9}$ Earlier microgravity research includes two-phase flow regime mapping and flow transitions; nucleate and pool boiling studies included critical heat flux enhancements; heat pipes and capillary pumped loops; and the development of diagnostic tools. More recently, new areas of investigations have begun which include fine particulate matter, fluidized beds, and gas-liquid flow through packed bed reactors. ${ }^{10}$ Although most of this work is ground-based, NASA does have near term plans to make use of the ISS. The following section briefly discusses the related experiments planned for the ISS within the next five years.

\section{Constrained Vapor Bubble Experiment (CVB)}

The constrained vapor bubble (CVB) experiment is currently planned for operations aboard the ISS in 2005. This experiment is both a fundamental study of interfacial fluid physics with evaporative heat transfer, as well as a hardware investigation of practical aspects of heat pipes, loop heat pipes (LHP), and capillary pumped loop (CPL) evaporators. Currently, LHP and CPL wicks are not designed from a first principles approach, because the boiling limit at the wick's liquid/vapor evaporator interface is not sufficiently understood. Without the ability to predict this maximum performance capability of two-phase systems, present-day spacecraft thermal control engineers must use trial-and-error methods. The exact reasons why the "burnout" limit is reached for various wick designs is unknown. The CVB experiment is a clever attempt to isolate a single evaporative pore with a single evaporating meniscus, and carefully measure this "burnout" limit and subsequent rewetting. The key aspect of the CVB is the transparent quartz cuvette that allows microscopic optical interferometry to precisely determine variation of liquid layer thickness (and thus the curvatures) and therefore pressure field changes in the vicinity of the liquid/vapor interface. Use of a transparent cuvette also allows the observation of instability preceding the onset of dry-out or burn-out and rewetting to recover from the burn out. 


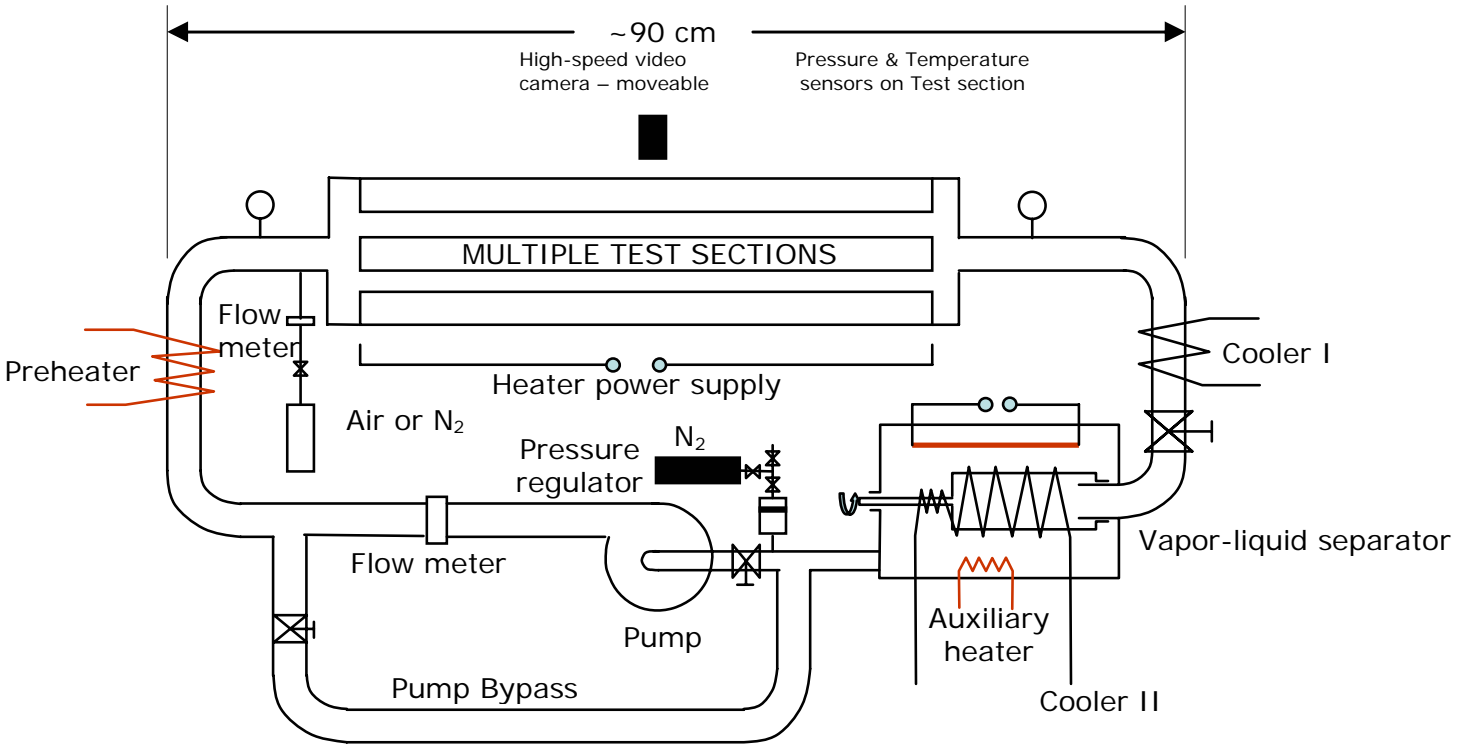

Figure 1. Preliminary concept for ISS TФffy.

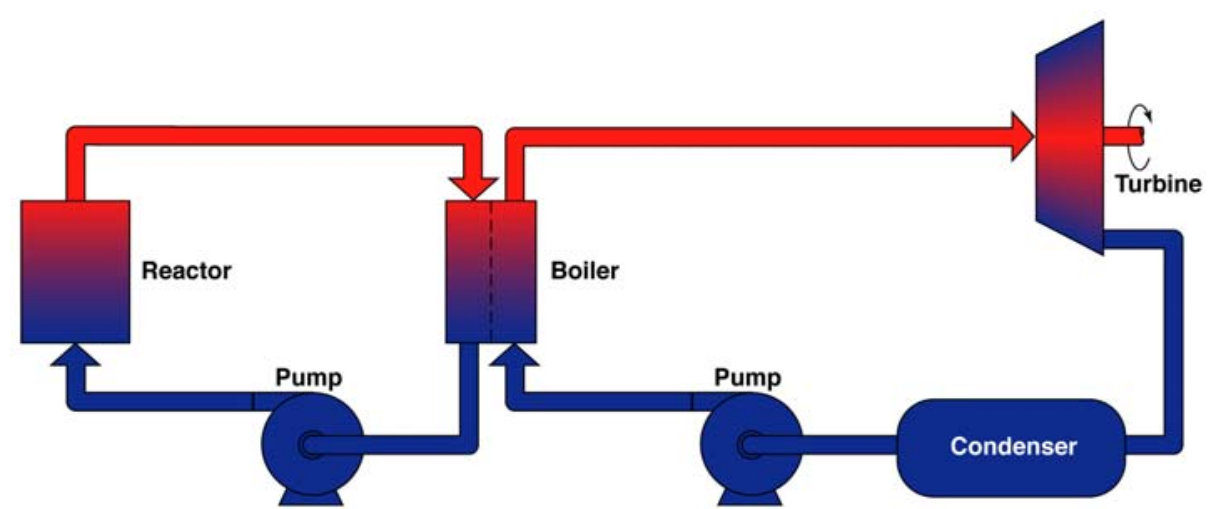

Figure 2. Schematic diagram of two fluid Rankine power conversion system.

Two-Phase Flow Facility (TФFFy)

Planning for a facility to conduct a range of multiphase flow experiments was initiated this year in parallel with the workshops. It is critical that a facility be available with the flexibility to conduct small scale experiments including phase change (boiling/condensation) and flow through various components commonly encountered in two phase systems. A science panel has been convened to provide guidance on the most effective use of TФFFy, but preliminary plans are to integrate the facility into the ISS Fluid Integrated Rack (FIR) by 2009. Figure 1 depicts a preliminary flow schematic and illustrates the concept of multiple test sections.

One of the first uses of this facility may be a small experiment including a boiler, condenser, and a Rotary Fluid Management Device (RFMD) to simulate a small Rankine cycle using a surrogate fluid. A simple schematic of a Rankine cycle is illustrated in figure 2 . The surrogate fluid experiments will be used to evaluate operational limits of the components, establish startup and shut-down strategies and acquire thermal/fluid data critical to this highly efficient power plant. This experiment would support NASA's Project Prometheus which is making significant strategic investments in space nuclear fission power and electric propulsion technologies to enable a new class of missions with capabilities well beyond those currently possible with chemically powered systems.

\section{ROADMAP}

The process used by the Microgravity Fluid Physics Program to develop a detailed strategic roadmap involved combining and consolidating the workshop recommendations as well as aligning the recommendations with the higher level OBPR roadmap 
(specifically questions $4 \mathrm{a}$ and $4 \mathrm{~b}$ ). In parallel to these workshops, OBPR also conducted a series of workshops which also influenced the final outcome. The following section provides the elements of the roadmap that will lead to successful implementation of many new technologies for advanced life support and power and propulsion systems. The scope of research has been divided into life support and power and propulsion to align with $4 \mathrm{a}$ and $4 \mathrm{~b}$. However, strong synergy exists and the implementation will include significant commonality between the two.

Research Focus: Advanced Life Support (Question 4a) NASA's efforts in advanced life support are directed toward research and technology developments that enable life support self-sufficiency thus permitting humans to carry out research and exploration activities productively in space. This research includes the development of technologies that will reduce the equivalent system mass for spacecraft subsystems, including mass, volume, power, and crew time, thus allowing for larger payloads for science and exploration.

The primary long-term research and technology challenge for delivering life support systems to sustain crews living and working in space for extended periods departs from the largely open systems of the past and current systems, and moves toward effective closure of the air, water, and waste systems by 2016. Elements of advanced life support systems and their subsystems typically involve multiphase flows, chemical reactions and heat and mass transport processes (examples include atmosphere, thermal, and humidity control, gas/liquid separation in grey water processing, and water recovery from urine). Multiphase flows such as those used with separation processes and associated heat and mass transfer, are intrinsically gravity sensitive. Therefore, experimental characterization of multiphase flow systems under reduced microgravity, or appropriately scaled conditions in ground-based facilities, will be essential for the development of life support system performance models and eventual validation.

\section{Research End Points}

- $\quad$ Improve performance and reliability of advanced life support system using two-phase technology. Two-phase technology is required for many life support systems including the management and processing of drinking and hygienic water; collection, processing and recovery of waste water; food management including production and storage; and environmental control such as temperature and humidity.
- Improve performance of gas/liquid/solid separation and mixing technologies for space and terrestrial applications. Efficient and reliable liquid-gas separation is essential for most of the waste recycling processes. For example most pumps work with liquid only and even small gas ingestion can easily lose prime and loss of operation. Better predictability of phase distribution and performance of separation devices in microgravity is needed.

- Enable efficient Packed Bed Reactors (PBR) operation in a micro- and hypo-gravity environment. PBR technology is used in many common chemical and biological processes such as the Sabatier reaction to produce oxygen and in the treatment of wastewater. Limited microgravity experiments on liquid-gas flows in packed beds have shown significant differences in flow characteristics from normal-gravity.

- Improve performance and reduce operational maintenance requirements of air ventilation/ filtration systems for long term space flight.

- Improve management of fine particulates in gas regeneration/recovery systems (minimize fines generation, transport, and deposition).

Research Targets 2004-2008

- Develop 3-D CFD predictive capabilities and verify the accuracy against existing reduced gravity data.

- $\quad$ Extend the 3-D CFD model to other flow regimes of interest in low gravity based on appropriate direct numerical simulations. Results will be used for the development of suitable closure laws for the CFD model.

- $\quad$ Design and build multi-user two-phase test facility for ISS to conduct experiments on:

- Phase distribution, separation and control

- Packed bed reactor hydrodynamics.

- Design a suitably scaled test loop and characterize it during parametric experiments on earth in conjunction with ISS test loop.

- Design and build multi-user facility to conduct experiments on contact line dynamics.

- Review standards and metrics for particulate management; determine need/appropriateness for recommending modifications and characterize in-situ airborne particulates/aggregates in microgravity habitat environment and particulate population distribution inside ventilation ducts.

- Monitor/document time history of growth of filterblocking dust buildup in microgravity.

- Identify dynamics of fine particulates and aggregates in closed loop spacecraft environment. 
- $\quad$ Determine most likely fundamental deposition and population mechanisms for fine particles in critical locations.

- Develop initial predictive/design models for mitigation of particulate buildup in critical locations.

- $\quad$ Evaluate state-of-the-art for monitoring particulate build-up in closed-loop spacecraft systems.

- Develop/demonstrate emerging technologies for solid/liquid separation that do not depend on settling (e.g., acoustic separation).

- Evaluate potential for minimizing fines generation, and mitigation through equipment/protocol modifications.

- Investigate/evaluate use of simplified granular beds which incorporate microgravity in design to prevent channeling, promote heat transfer and minimize fines generation.

- $\quad$ Consider improved ways to provide heat transfer to granular beds under ISS pressure or vacuum conditions.

$\underline{\text { Research Targets 2009-2016 }}$

- $\quad$ Perform pretest predictions using the 3-D CFD code for experiments to be performed on the ISS.

- Conduct experiments and test predictive tools on multi-user two-phase test facility on ISS for:

- Phase distribution, separation and control

- Packed bed reactor hydrodynamics.

- Conduct experiments and test predictive tools on contact line dynamics.

- Conduct ISS experiments on liquid-gas flows in packed beds (mass transfer, reactions).

- Modify the 3-D CFD code, as required, to produce a combined comprehensive modeling effort for multiphase heat transfer and flow leading to user design code.

- Perform a detailed verification and validation of the user design code.

- Measure and model diffusion-driven aggregation of airborne fine particulates in microgravity under controlled flow conditions.

- Measure and model deposition, redispersion, entrainment and population changes of representative microgravity airborne particulates in controlled flows near boundaries and through grids or other large-opening arrays.

- Measure and model physical properties and deagglomeration/redispersion behavior of microgravity-representative 'dust beds' consolidated under various airflow conditions.

- Develop enhanced and/or more representative design rules for ventilation filter systems in space as additional data is accumulated from ongoing monitoring.
- $\quad$ Characterize potential fines that may be introduced from extra-terrestrial excursions.

- Evaluate/establish potential mitigation or cleaning strategies for dust on moving parts and seals and minimize introduction of mineral fines to $\mu$ g-crew environment after lunar or Martian excursions.

- Investigate deposition/ migration of fine particulates on surfaces and into narrow openings.

- Develop reliable, low power, small mass, volume particulate handling technologies for transport and separation in chemical processing of gas-solid and liquid-solid systems (dielectrophoresis, freeze drying, acoustic separation, compaction and containment of dry solid waste/rejected particulates).

- Develop alternative packed bed configurations. Evaluate heat transfer, thermo-mechanical stresses and potential for fines generation with alternativegeometries.

- Investigate heat transfer and potential fines generation in free floating and/or rotating granular systems.

Research Focus: Power and Propulsion (Question 4b) Exploration beyond LEO requires safe, efficient, and economical in-space transportation with extensive power and infrastructure for humans to remain healthy, safe, and productive. At present, we are pushing the limits of innovation with solar and chemical power. It is only by harnessing the tremendous energy within the atom that we can aspire to fundamentally improve our capability for Solar System exploration and enable missions of greater longevity, flexibility, and, therefore, significantly improved scientific return. Fission-based nuclear electric propulsion is needed to provide continuous power to maneuver a spacecraft throughout its mission or allow a spacecraft to visit multiple destinations per mission. Nuclear power can also provide much greater amounts of power to enable extended scientific research and the capability to transmit extensive data back to Earth.

Power and propulsion systems needed for exploration of space will require devices that depend on multiphase flow and heat transfer processes to achieve low mass, high efficiency, and low cost. However, there are currently large uncertainties surrounding the behavior of multiphase flows in reduced gravity. If multiphase systems and processes are to be used in space, then reliable physically based predictive tools will need to be developed and used by NASA for design and analysis of candidate propulsion and power systems and subsystems. 
Research End Points

- Enable development of reliable power systems for space power and nuclear electric propulsion through improved understanding of reduced gravity effects on phase change and on multiphase systems. Two-phase technology is required in relatively low power production (portable fuel cells) as well as very large systems (nuclearelectric propulsion). For nuclear electric propulsion, the Rankine cycle offers the highest efficiency, small radiator weight/area, and scalability to multi-megawatt power levels. Lack of long-duration microgravity data on two-phase flow and boiling heat transfer have been the main hurdles for implementing this promising technology. Use of desirable Proton Exchange Membrane (PEM) fuel cells has also been hampered by lack of data on two-phase flow and effective liquid-gas separation issues in microgravity.

- Reduce weight and increase reliability of storage and management of propellant and other liquids (including cryogenic) in low-g.

\section{Research Targets 2004-2008}

- Develop 3-D CFD predictive capabilities and verify the accuracy against existing reduced gravity data.

- Extend the 3-D CFD model to other flow regimes of interest in low gravity based on appropriate direct numerical simulations. Results will be used for the development of suitable closure laws for the CFD model.

- Design and build multi-user two-phase test facility for ISS to conduct experiments on:

- Boiling, condensation, two phase heat transfer coefficients, and Critical Heat Flux (CHF)

- Two-phase instability phenomena including flow through parallel channels, density wave oscillation and phase accumulation within components

- Two-phase flow through components and porous media.

- Design a suitably scaled test loop and characterize it during parametric experiments on earth in conjunction with ISS test loop.

- Use the test loop to verify two-phase elements of the Rankine cycle with scalability to liquid metal conditions.

- Design and build multi-user facility to conduct experiments on contact line dynamics.

- Design and build small scale facility to conduct experiments on cryogenic storage and handling.
Research Targets 2009-2015

- Perform pretest predictions using the 3-D CFD code for experiments to be performed on the ISS.

- Conduct experiments and test predictive tools on multi-user two-phase test facility on ISS for:

- Boiling, condensation, heat transfer coefficients, and CHF

- Two-phase instability phenomena including flow through parallel channels, density wave oscillation and phase accumulation within components

- Two-phase flow through components and porous media.

- Conduct experiments and develop predictive techniques on cryogenic storage and handling.

- Modify the 3-D CFD code, as required, to produce a combined comprehensive modeling effort for multiphase heat transfer and flow leading to user design code.

- Perform a detailed verification and validation of the user design code.

\section{CONCLUSIONS}

NASA is embarking on its ambitious plan to develop advanced technology to realize the dream of human tended exploration missions. Understanding of fluid behavior in biological and physical systems under the low-gravity environment of space is imperative. The Microgravity Fluid Physics Program has developed a research roadmap to help close some key gaps in knowledge and enable implementation of new technologies that improve efficiency and reliability of spacecraft systems. The first steps towards implementing the plan are about to begin under the auspices of the new Human Research Initiative included in NASA's fiscal year 2004 budget currently before the U.S. Congress. This is just the beginning of what can be a broad research program well integrated to support the critical needs of NASA's advanced exploration technologies.

\section{REFERENCES}

1. "NASA Biological and Physical Research Enterprise Strategy,” October 2003. Electronically available at: http://spaceresearch.nasa.gov/docs/OBPRStrategy.pdf

2. Kohl, F.J., Singh, B.S., Alexander, J.I., Shaw, N.J., Hill, M.E., and Gati, F.G., "The NASA Microgravity Fluid Physics Program-Knowledge for Use on Earth and Future Space Missions," IAC-02T.4.02 (NASA/TM-2002-212009), 53rd International Astronautical Congress, October 2002. 
3. “Fine Particulate Workshop," NASA Glenn Research Center and National Center for Microgravity Research, May 2003. Electronically available at:

http://www.ncmr.org/events/particulate/

4. "Multiphase Flow in Space Power and Propulsion Workshop and Fluid Stability and Dynamics Workshop," NASA Glenn Research Center and National Center for Microgravity Research, May 2003. Electronically available at: http://www.ncmr.org/events/multiphase/

5. "Microgravity Fluid Management Symposium," NASA CP-2465, NASA Lewis Research Center, 1986.

6. "Workshop on Research Needs in Space Thermal Systems and Processes for Human Exploration of Space," NASA Glenn Research Center and National Center for Microgravity Research, July 2000. Electronically available at:

http://microgravity.grc.nasa.gov/6712/thermal/workshop. html
7. "Workshop on Research Needs in Fluids Management for the Human Exploration of Space," NASA Glenn Research Center, September 2000. Electronically available at: http://www.ncmr.org/events/fluidsmgmt/

8. "Microgravity Research in Support of Technologies for the Human Exploration and Development of Space and Planetary Bodies," National Research Council, 2000.

9. Singh, B.S., "Multiphase Flow and Phase Change in Microgravity: A Technical Overview," 3rd ASME/JSME Joint Fluids Engineering Conference, July 1999.

10. Motil, B.J., Balakotaiah, V., and Kamotani, Y., "Gas-Liquid Two-Phase Flows Through Packed Beds in Microgravity," AIChE J., vol. 49, no. 3, pp. 557-565 (2003). 



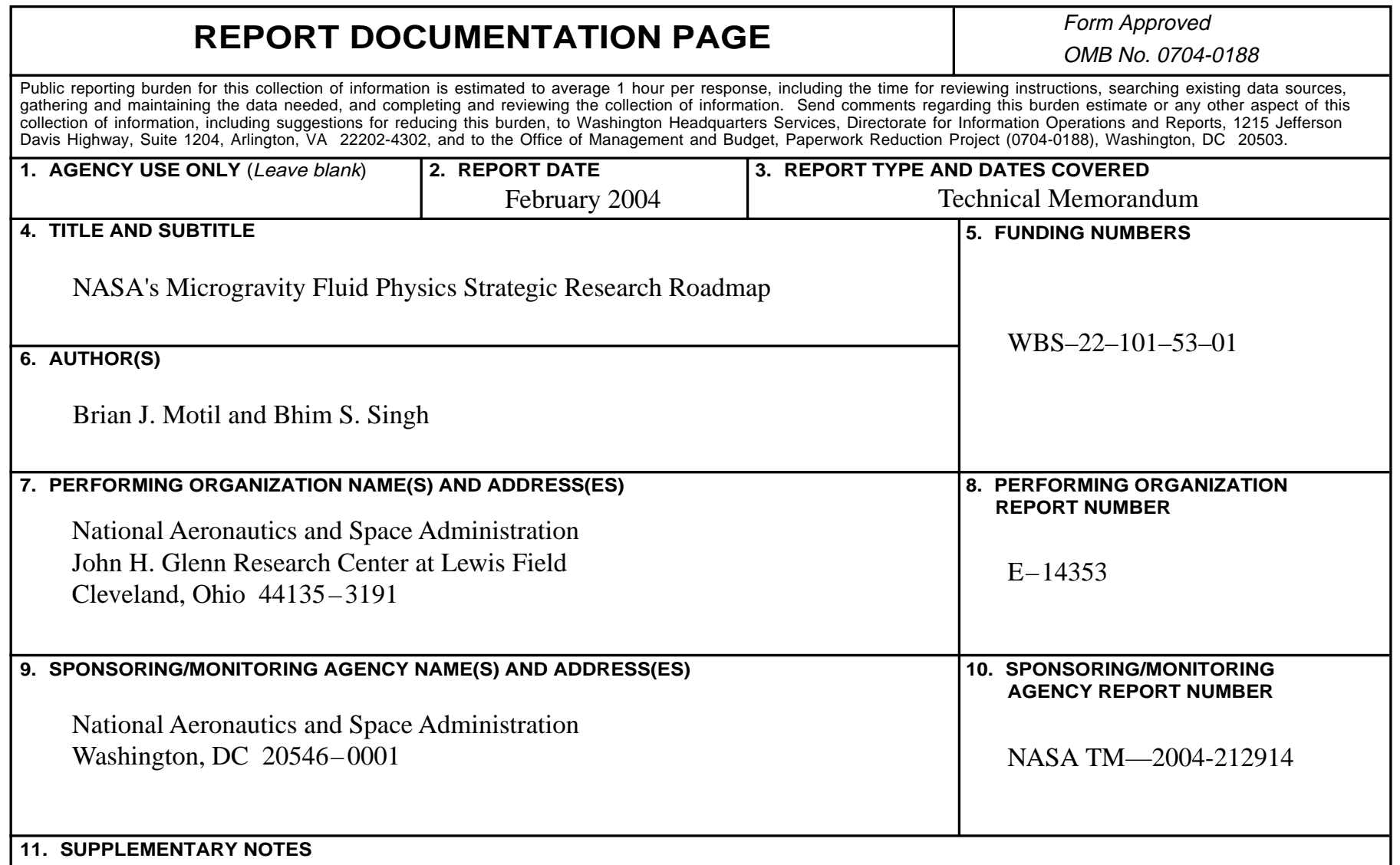

Prepared for the 42nd Aerospace Sciences Meeting and Exhibit sponsored by the American Institute of Aeronautics and Astronautics, Reno, Nevada, January 5-8, 2004. Responsible person, Brian J. Motil, organization code 6712, 216-433-6617.

12a. DISTRIBUTION/AVAILABILITY STATEMENT 12b. DISTRIBUTION CODE

Unclassified - Unlimited

Subject Category: 34

Distribution: Nonstandard

Available electronically at http://gltrs.grc.nasa.gov

This publication is available from the NASA Center for AeroSpace Information, 301-621-0390.

13. ABSTRACT (Maximum 200 words)

The Microgravity Fluid Physics Program at NASA has developed a substantial investigator base engaging a broad crosssection of the U.S. scientific community. As a result, it enjoys a rich history of many significant scientific achievements. The research supported by the program has produced many important findings that have been published in prestigious journals such as Science, Nature, Journal of Fluid Mechanics, Physics of Fluids, and many others. The focus of the program so far has primarily been on fundamental scientific studies. However, a recent shift in emphasis at NASA to develop advanced technologies to enable future exploration of space has provided motivation to add a strategic research component to the program. This has set into motion a year of intense planning within NASA including three workshops to solicit inputs from the external scientific community. The planning activities and the workshops have resulted in a prioritized list of strategic research issues along with a corresponding detailed roadmap specific to fluid physics. The results of these activities were provided to NASA's Office of Biological and Physical Research (OBPR) to support the development of the Enterprise Strategy document. This paper summarizes these results while showing how the planned research supports NASA's overall vision through OBPR's organizing questions.

14. SUBJECT TERMS

Fluid mechanics; Microgravity; Two-phase flow; Particulates; Advanced human support

\begin{tabular}{|c|c|c|}
\hline $\begin{array}{c}\text { 17. SECURITY CLASSIFICATION } \\
\text { OF REPORT } \\
\text { Unclassified }\end{array}$ & $\begin{array}{c}\text { 18. SECURITY CLASSIFICATION } \\
\text { OF THIS PAGE } \\
\text { Unclassified }\end{array}$ & $\begin{array}{c}\text { 19. SECURITY CLASSIFICATION } \\
\text { OF ABSTRACT } \\
\text { Unclassified }\end{array}$ \\
\hline
\end{tabular}

NSN 7540-01-280-5500

Standard Form 298 (Rev. 2-89)

Prescribed by ANSI Std. Z39-18
298-102

15. NUMBER OF PAGES

16. PRICE CODE

20. LIMITATION OF ABSTRACT 